\section{RMD Open}

Rheumatic \&

Musculoskeletal Diseases

\title{
Regulation of peripheral classical and non-classical monocytes on infliximab treatment in patients with rheumatoid arthritis and ankylosing spondylitis
}

\author{
Daniel Aeberli, ${ }^{1}$ Richard Kamgang, ${ }^{1}$ Deepak Balani, ${ }^{1,2}$ Willy Hofstetter, ${ }^{2}$ \\ Peter M Villiger, ${ }^{1}$ Michael Seitz ${ }^{1}$
}

To cite: Aeberli $D$, Kamgang R, Balani D, et al. Regulation of peripheral classical and non-classical monocytes on infliximab treatment in patients with rheumatoid arthritis and ankylosing spondylitis. RMD Open 2016;2:e000079. doi:10.1136/rmdopen-2015000079

- Prepublication history for this paper is available online. To view these files please visit the journal online (http://dx.doi.org/10.1136/ rmdopen-2015-000079)

Received 29 January 2015 Revised 7 October 2015 Accepted 20 October 2015

\section{(1) CrossMark}

\section{${ }^{1}$ Department of}

Rheumatology, Immunology and Allergology, University Hospital of Bern, Bern, Switzerland

${ }^{2}$ Group for Bone Biology \& Orthopaedic Research, Department of Clinical Research, University of Bern, Bern, Switzerland

Correspondence to Dr Michael Seitz; michael.seitz@insel.ch

\section{ABSTRACT}

Objective: To investigate the regulatory effect of tumour necrosis factor (TNF) blockade with infliximab on the distribution of peripheral blood monocyte subpopulations in patients with rheumatoid arthritis (RA) and ankylosing spondylitis (AS).

Methods: Purified CD11b+CD14+ monocytes from 5 patients with RA and 5 AS were analysed ex vivo before and after infliximab treatment by flow cytometry for CD16, CD163, CD11b, C-C chemokine receptor type 2 (CCR2) and CXC chemokine receptor 4 (CXCR4) at baseline and at days 2, 14, 84 and 168 after the first infliximab administration. Serum levels of the stromal cell-derived factor (SDF)-1 and monocyte chemotactic peptide (MCP)-1 at different time points were measured in either patient group before and on infliximab treatment.

Results: Anti-TNF treatment with infliximab led to a significant increase of circulating CD11b+ non-classical and a concomitantly decrease of CD11b+ classical monocytes, to a decline in SDF-1 levels and reduced expression of CCR2 and CXCR4 on non-classical monocyte subpopulation.

Conclusions: Our study shows, that TNF $\alpha$ blockade by infliximab resulted in a dichotomy of the regulation of classical and non-classical monocytes that might have substantial impact on inhibition of osteoclastogenesis and of subsequent juxta-articular bone destruction and systemic bone loss in RA and AS.

\section{INTRODUCTION}

Tumour necrosis factor (TNF) inhibition leads to a reduction of soluble cell adhesion molecules, chemokines and their receptors in patients with rheumatoid arthritis (RA) ${ }^{12}$ or ankylosing spondylitis (AS). ${ }^{3}$ In Crohn's disease, infliximab therapy has been found to increase the frequency of circulating CD14 $+\mathrm{CD} 16+$ monocytes. $^{4}$ These non-classical

\section{Key questions}

What is already known about this subject?

- Tumour necrosis factor (TNF) inhibition leads to a reduced bone resorbing activity of osteoclast precursor cells in patients with rheumatoid arthritis (RA) or ankylosing spondylitis (AS).

What does this study add?

- We demonstrated that anti-TNF $\alpha$ treatment response on infliximab in patients with RA and AS is associated with a rapid decline in the number of circulating classical monocytes, reduced expression of CXC chemokine receptor 4, C-C chemokine receptor type 2 and circulating stromal cell-derived factor-1.

How might this impact on clinical practice?

- Provide a mechanistic understanding of the antiosteoclastogenic and bone preserving effect of anti-TNF $\alpha$ treatment on infliximab in patients with RA and AS.

monocytes have been found to produce large amounts of $\mathrm{TNF}^{5}$ but are not able to differentiate into osteoclasts, ${ }^{6}$ whereas classical monocytes $(\mathrm{CD} 14+\mathrm{CD} 16-)$ are mainly producers of interleukin- $10^{6}$ and are able to differentiate into osteoclasts. ${ }^{6}$ Differential therapeutic regulation of these monocyte subsets may explain the bone-sparing effect of TNF inhibitors. This has yet not been elucidated ex vivo.

\section{METHODS}

Patients with RA according to the ACR 1987 revised criteria ${ }^{7}$ and patients with AS according to the New York criteria ${ }^{8}$ were included in the present study. Patients who fulfilled the $\operatorname{EULAR}^{9}$ and $\mathrm{ASAS}^{10}$ response criteria to treatment with infliximab after 3 months were analysed based on data sets obtained at 
all defined time points during the entire study period. Concomitant medications such as corticosteroids $>7.5 \mathrm{mg}$ prednisone equivalent daily, bisphosphonates, antiepileptics, heparin, oestrogens, testosterone, thiazids and ACE inhibitors were exclusion criteria. Repetitive blood samples from patients were obtained by venipuncture. To elucidate changes of monocyte subsets, positively selected (CD14 microbeads; Miltenyi Biotec, Bergisch-Gladbach, Germany) CD14+ peripheral blood monocytes were measured for CD14, CD16, CD163, CD11b, C-C chemokine receptor type 2 (CCR2) and CXC chemokine receptor 4 (CXCR4; antibodies all from BD Pharmingen, San Diego, California, USA) expression by FACS at baseline and days 2, 14, 84 and 168 after the first infliximab administration. ${ }^{11}$ Infliximab was administered intravenously at baseline and after 2, 4, 6,12 and 24 weeks $(3 \mathrm{mg} / \mathrm{kg}$ in patients with $\mathrm{RA}$ and $5 \mathrm{mg} / \mathrm{kg}$ in patients with AS) ${ }^{11}$ and adjusted according to clinical response thereafter. Blood was examined for changes in monocytes subsets, circulating levels of stromal cell-derived factor (SDF)-1 (Quantikine Kit (R\&D Systems, Minneapolis, Minnesota, USA) and of monocyte chemotactic peptide (MCP)-1 (BD Pharmingen) which were determined by ELISA. The minimum detectable dose of SDF-1 was $18 \mathrm{pg} / \mathrm{mL}$ and of MCP-1 $19 \mathrm{pg} / \mathrm{mL}$.

Because of only 10 patients tested we used repeated measures analysis of variance and post hoc Bonferroni's Multiple Comparison Test (95\% CIs), significant results $(\mathrm{p}<0.05)$ are depicted with an asterisk. Exact $\mathrm{p}$ values were calculated by one-tailed paired t test. Analysis and graphs were performed using prism 5 (GraphPad V.5.0).

\section{RESULTS}

\section{Patient's characteristics prior to infliximab treatment}

Baseline characteristics of the 10 patients included in the present study are shown in table 1 . Based on the strict exclusion criteria for co-medication and for definition of active disease and of treatment response, the number of finally included patients was only 10. As anticipated, the majority of RA patients were postmenopausal middle-aged females, whereas the AS group included only younger and middle-aged males. Therapy with symptomatic and/or disease-modifying antirheumatic drugs remained unchanged during the study period. Two patients with AS had no co-medication at study entry and during the entire study period. Before the first infliximab infusion, all patients had active disease according to the Disease Activity Score 28 $(\text { DAS28 })^{9}$ and Bath Ankylosing Spondylitis Disease Activity Index (BASDAI). ${ }^{12}$

\section{Increase of non-classical and decrease of classical} monocytes during infliximab treatment

Throughout the study period, the number of CD11b $+\mathrm{CD} 14+$ monocytes remained constant in either patient population (range 84.8-98.6\%). However, the monocyte

\begin{tabular}{|c|c|c|}
\hline & RA $(n=5)$ & AS $(n=5)$ \\
\hline Female (n) & 4 & 0 \\
\hline Male $(n)$ & 1 & 5 \\
\hline Age, years (range) & $48.6(39-59)$ & $37.2(28-47)$ \\
\hline $\begin{array}{l}\text { Disease duration, years } \\
\text { (range) }\end{array}$ & $5.2(1.5-11)$ & $5.48(3-10)$ \\
\hline DAS28, ${ }^{9}$ mean (range) & $\begin{array}{l}4.93(3.54- \\
5.94)\end{array}$ & - \\
\hline BASDAI, $^{12}$ mean (range) & - & $\begin{array}{l}4.27(3.83- \\
4.6)\end{array}$ \\
\hline $\mathrm{ESR}, \mathrm{mm} / \mathrm{h}$, mean (range) & $21(10-41)$ & $38(12-71)$ \\
\hline CRP, mg/L, mean (range) & $6(3-17)$ & $27(3-49)$ \\
\hline $\mathrm{RF}+(\%)$ & 80 & 0 \\
\hline $\mathrm{aCCP}+(\%)$ & 80 & 0 \\
\hline HLA-B27+ (\%) & 0 & 100 \\
\hline Prednisone 7.5 mg/d (n) & 3 & 0 \\
\hline Methotrexate $15 \mathrm{mg} / \mathrm{w}(\mathrm{n})$ & 2 & 0 \\
\hline Leflunomide 20 mg/d (n) & 2 & 0 \\
\hline NSAIDs (n) & 3 & 3 \\
\hline
\end{tabular}

subpopulations of interest exhibited a contrasting regulation pattern on infliximab treatment both in patients with RA and AS (figure 1). Whereas the nonclassical (CD11b+CD14+CD163-CD16+) subpopulation increased over time (for RA: range of $7.1 \%$ up to 25.5.\%; range of $p$ value compared with baseline from 0.09 to 0.013 ; for AS: range of $3.4 \%$ up to $40.3 \%$; range of $p$ value compared with baseline from 0.34 to 0.045 ), the classical (CD11b+CD14+CD163+CD16-) subpopulation decreased (for RA: range of $40.1 \%$ down to $0.2 \%$, range of $p$ value compared with baseline from 0.14 to 0.003 ; for AS: range $47 \%$ down to $1.1 \%$, range of $\mathrm{p}$ value from 0.023 to 0.002 ).

\section{Downregulation of circulating ligand levels (SDF-1 and MCP-1) and expression of their receptors (CCR2 and CXCR4) on infliximab treatment}

Serum levels of the corresponding cytokines (SDF-1 and MCP-1) at different time points were measured concomitantly in either patient group before and on infliximab treatment. We found a reduction of circulating SDF-1 levels over time in patients with RA and AS and less significant also of MCP-1 levels after 6 months in patients with RA only (figure 2A). In addition, we observed a significant and rapid downregulation of the percentage of CXCR4+ and CCR2+ classical monocytes 2 days, 2 weeks, 3 months and 6 months after initiation of infliximab treatment compared with baseline values in patients with RA ( $p$ values of $0.026,0.037,0.028$ and 0.02 ; $p$ values of $0.046,0.029,0.029$ and 0.029 , respectively; figure $2 \mathrm{~B}$ ).

\section{DISCUSSION}

In the present study, we demonstrated that in patients with RA and AS anti-TNF $\alpha$ treatment response on 

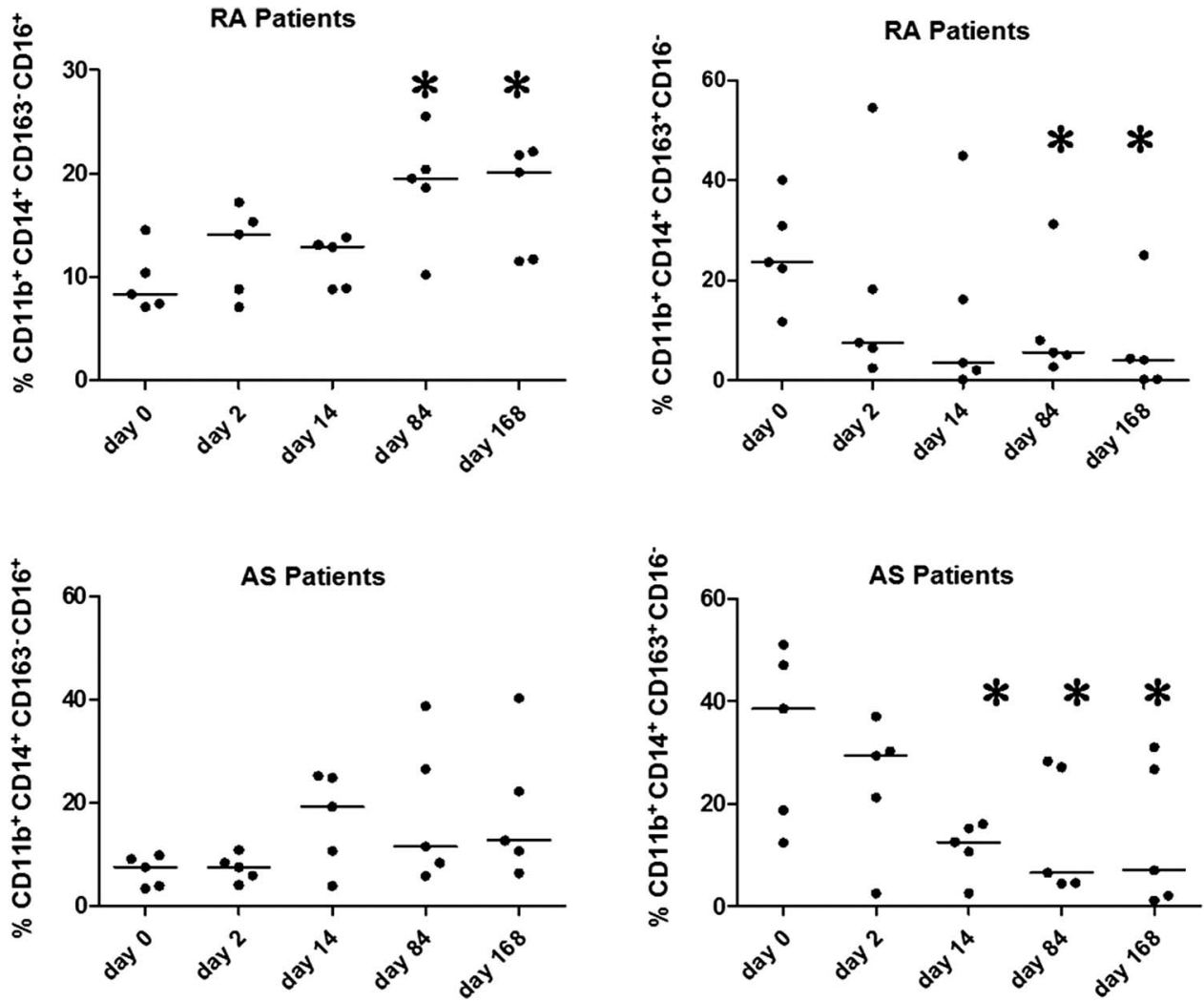

Figure 1 Changes in non-classical (CD11b+CD14+CD163-CD16+) and classical (CD11b+CD14+CD163+CD16-) monocytes over time in patients with rheumatoid arthritis (RA) and ankylosing spondylitis (AS). Data are shown as percentage of CD11b + CD14+ cells and median ( $\left.{ }^{*} \mathrm{p}<0.05\right)$.

infliximab is associated with a rapid decline in the number of circulating classical (CD11b+CD14+CD163 +CD16-) monocytes with reduced expression of CXCR4, CGR2 and decreased levels of circulating SDF-1. In contrast, we observed a constant accumulation of circulating non-classical (CD11b+CD14+CD163-CD16+) monocytes. Only in patients with RA we found also a decline of circulating MCP-1. Thus, our study shows, that successful $\mathrm{TNF} \alpha$ blockade by infliximab resulted in a dichotomy in the regulation of monocytes subpopulations that may have $\mathrm{n}$ substantial impact on reduced bone resorbing activity of osteoclast precursor cells (OPCs) that we have observed in a previous study. ${ }^{11}$

In order to get a deeper insight into the nature of potential inhibitory mechanisms, we focused on factors influencing the recruitment and migration behaviour of these cells. We first demonstrated that besides reducing the pool of circulating classical CD163+CD16- monocytes, infliximab treatment did also reduce the amount of CD163+CD16- cells bearing the chemokine receptors CXCR4 and CCR2 and concomitantly reduced the levels of corresponding circulating chemokines. These findings may suggest that besides promotion of apoptosis of monocytes as described previously ${ }^{13}$ a specific inhibition of recruitment and/or trafficking of classical monocytes and of subsequent osteoclasts development at inflammatory sites might contribute to the inhibition of bone resorption by infliximab in $\mathrm{TNF} \alpha$-mediated chronic inflammatory processes. Regarding the inhibition of recruitment of OPCs from bone marrow corresponding mechanisms have been already described previously in patients with psoriatic arthritis. ${ }^{14}$ The inhibition of SDF-1 secretion, that is, from activated synovial fibroblasts and reduced CXCR4 expression on circulating classical monocytes ${ }^{15}$ might finally inhibit recruitment, directed trafficking into inflamed peripheral tissues and subsequent osteoclastogenesis.

The peripheral pooling of CD16+ monocytes and of Th1 cells ${ }^{16}$ on infliximab treatment might reflect an antiinflammatory effect which is hypothetically mediated by the downregulation of expression of adhesion molecules on endothelial cells and by subsequent inhibition of transmigration of inflammatory cells through postcapillary venules into inflammatory sites. ${ }^{17} 18$ Our finding of a reduced recruitment of CD163+ monocytes during infliximab treatment is also in good accordance with previous results demonstrating a reduced influx of CD163+ monocytes into the synovial compartment of patients with RA and spondyloarthritis, ${ }^{19}$ a reduced osteoclastogenesis in the synovial compartment of patients with psoriatic arthritis ${ }^{15}$ and with the reversal of the increased frequency of CD11b ${ }^{\text {high }}+$ osteoclast precursors and enhanced osteoclastogenesis in TNF-tg mice on anti-TNF $\alpha$ treatment in vivo. $^{20}$ 
Figure 2 (A) Reduction of circulating stromal cell-derived factor (SDF)-1 levels over time in patients with rheumatoid arthritis (RA) and ankylosing spondylitis (AS) and less significant also of monocyte chemotactic peptide (MCP)-1 levels after 6 months in patients with RA only. Data are shown as absolute values and median $\left({ }^{*} \mathrm{p}<0.05\right)$.

(B) Downregulation of the percentage of CXCR4+ and CCR2+ classical monocytes 2 days, 2 weeks, 3 months and 6 months after initiation of infliximab treatment compared with baseline values in patients with RA. Data are shown as percentage of CD11b+CD14 +CD163+CD16- cells and median $\left({ }^{*} \mathrm{p}<0.05\right)$.
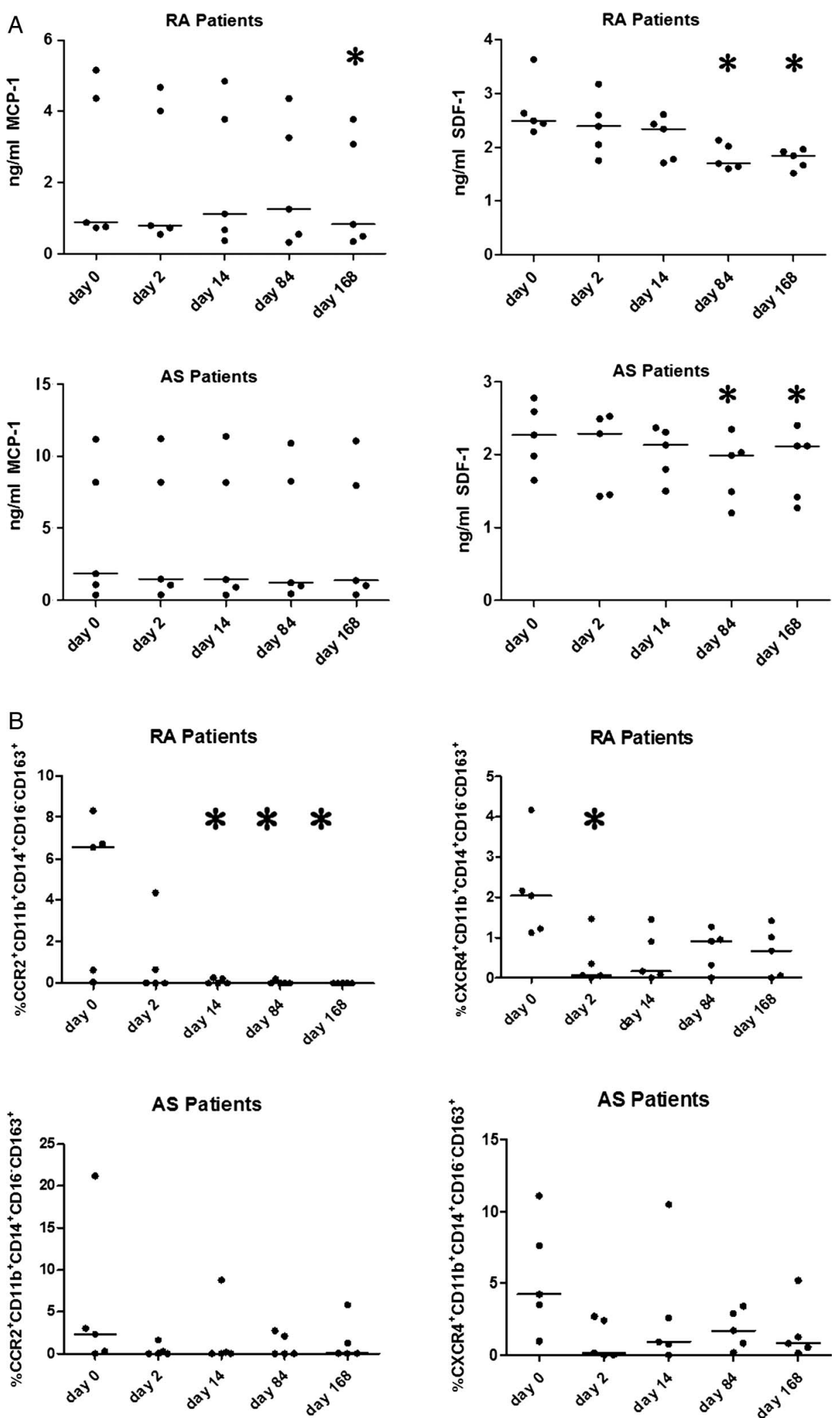

A limitation of our study is the low numbers of included patients that could be analysed longitudinally.

Acknowledgements The authors thank all participating patients.

Contributors DA, MS, WH and PMV were involved in conception and design, analysis and interpretation of data. RK and DB took part in acquisition of data. DA, MS and WH took part in drafting the article. MS, WH and PMV took part in revising it critically for important intellectual content. DA, MS and WH took part in final approval of the version to be published.

Funding The study has been funded by a grant of the Swiss National Research Foundation to MS (3200B0-11905/1).

Competing interests None declared. 
Ethics approval The study design was approved by the ethics committee of the canton of Bern and a written informed consent was obtained from each patient before study enrolment.

Provenance and peer review Not commissioned; externally peer reviewed.

Data sharing statement No additional data are available.

Open Access This is an Open Access article distributed in accordance with the Creative Commons Attribution Non Commercial (CC BY-NC 4.0) license, which permits others to distribute, remix, adapt, build upon this work noncommercially, and license their derivative works on different terms, provided the original work is properly cited and the use is non-commercial. See: http:// creativecommons.org/licenses/by-nc/4.0/

\section{REFERENCES}

1. Gonzalez-Gay MA, Garcia-Unzueta MT, De Matias JM, et al. Influence of anti-TNF-alpha infliximab therapy on adhesion molecules associated with atherogenesis in patients with rheumatoid arthritis. Clin Exp Rheumatol 2006;24:373-9.

2. Eriksson C, Rantapaa-Dahlqvist S, Sundqvist KG. Changes in chemokines and their receptors in blood during treatment with the TNF inhibitor infliximab in patients with rheumatoid arthritis. Scand J Rheumatol 2013;42:260-5.

3. Ahern MJ, Campbell DG, Weedon $\mathrm{H}$, et al. Effect of intra-articular infliximab on synovial membrane pathology in a patient with a seronegative spondyloarthropathy. Ann Rheum Dis 2008;67:1339-42.

4. Nazareth N, Magro F, Silva J, et al. Infliximab therapy increases the frequency of circulating CD16(+) monocytes and modifies macrophage cytokine response to bacterial infection. Clin Exp Immunol 2014;177:703-11.

5. Siedlar M, Strach M, Bukowska-Strakova K, et al. Preparations of intravenous immunoglobulins diminish the number and proinflammatory response of CD14+CD16++ monocytes in common variable immunodeficiency (CVID) patients. Clin Immunol 2011;139:122-32.

6. Komano Y, Nanki T, Hayashida K, et al. Identification of a human peripheral blood monocyte subset that differentiates into osteoclasts. Arthritis Res Ther 2006;8:R152.

7. Arnett FC, Edworthy SM, Bloch DA, et al. The American Rheumatism Association 1987 revised criteria for the classification of rheumatoid arthritis. Arthritis Rheum 1988;31:315-24.

8. van der Linden S, Valkenburg HA, Cats A. Evaluation of diagnostic criteria for ankylosing spondylitis. A proposal for modification of the New York criteria. Arthritis Rheum 1984;27:361-8.
9. van Gestel A, van Riel P. American College of Rheumatology preliminary definition of improvement in rheumatoid arthritis: comment on the article by Felson et al. Arthritis Rheum 1996;39:535-7.

10. Anderson JJ, Baron G, van der Heijde D, et al. Ankylosing spondylitis assessment group preliminary definition of short-term improvement in ankylosing spondylitis. Arthritis Rheum 2001;44:1876-86.

11. Gengenbacher M, Sebald HJ, Villiger PM, et al. Infliximab inhibits bone resorption by circulating osteoclast precursor cells in patients with rheumatoid arthritis and ankylosing spondylitis. Ann Rheum Dis 2008;67:620-4.

12. Brandt J, Westhoff $\mathrm{G}$, Rudwaleit $\mathrm{M}$, et al. [Adaption and validation of the Bath Ankylosing Spondylitis Disease Activity Index (BASDAI) for use in Germany]. Z Rheumatol 2003;62:264-73.

13. Catrina Al, Trollmo $\mathrm{C}$, af Klint $\mathrm{E}$, et al. Evidence that anti-tumor necrosis factor therapy with both etanercept and infliximab induces apoptosis in macrophages, but not lymphocytes, in rheumatoid arthritis joints: extended report. Arthritis Rheum 2005;52:61-72.

14. Ritchlin CT, Haas-Smith SA, Li P, et al. Mechanisms of TNF-alphaand RANKL-mediated osteoclastogenesis and bone resorption in psoriatic arthritis. J Clin Invest 2003;111:821-31.

15. Kim KW, Cho ML, Kim HR, et al. Up-regulation of stromal cell-derived factor 1 (CXCL12) production in rheumatoid synovial fibroblasts through interactions with $T$ lymphocytes: role of interleukin-17 and CD40L-CD40 interaction. Arthritis Rheum 2007;56:1076-86.

16. Aeberli D, Seitz $M$, Juni $P$, et al. Increase of peripheral CXCR3 positive T lymphocytes upon treatment of RA patients with TNF-alpha inhibitors. Rheumatology (Oxford) 2005;44:172-5

17. Tak PP, Taylor PC, Breedveld FC, et al. Decrease in cellularity and expression of adhesion molecules by anti-tumor necrosis factor alpha monoclonal antibody treatment in patients with rheumatoid arthritis. Arthritis Rheum 1996;39:1077-81.

18. Arijs I, De Hertogh G, Machiels K, et al. Mucosal gene expression of cell adhesion molecules, chemokines, and chemokine receptors in patients with inflammatory bowel disease before and after infliximab treatment. Am J Gastroenterol 2011;106:748-61.

19. Baeten D, Demetter P, Cuvelier CA, et al. Macrophages expressing the scavenger receptor CD163: a link between immune alterations of the gut and synovial inflammation in spondyloarthropathy. $J$ Pathol 2002;196:343-50.

20. Li P, Schwarz EM, O'Keefe RJ, et al. Systemic tumor necrosis factor alpha mediates an increase in peripheral CD11bhigh osteoclast precursors in tumor necrosis factor alpha-transgenic mice. Arthritis Rheum 2004;50:265-76. 